\title{
Cost effectiveness of prophylaxis in dental practice to prevent infective endocarditis
}

Department of Clinical Microbiology, Foresterhill, Aberdeen I M Gould

Health Services Research Unit, Aberdeen Royal Infirmary,

Foresterhill, Aberdeen J K Buckingham

Correspondence to: Dr I Gould, Department of Medical Microbiology, Aberdeen Royal Hospitals NHS Trust, Aberdeen Royal Infirmary, Foresterhill, Aberdeen AB9 2ZD.

Accepted for publication 18 January 1993

\author{
I M Gould, J K Buckingham
}

\begin{abstract}
Background-Although antimicrobial prophylaxis for infective endocarditis (IE) is common practice for many dental procedures, there is little information on whether it represents value for money. A study was performed to evaluate the effectiveness of prophylaxis for all at risk patients in routine dental practice with published data from the United Kingdom.

Methods-The risk of contracting infective endocarditis was calculated from published data to find (for high risk patients) both the annual number of deaths attributable to infective endocarditis and the number of high risk dental procedures performed without prophylaxis. Costs are estimated by examining the notes of 63 patients with proved IE during the decade 1980-90.

Results-Such prophylaxis is highly cost effective before dental extractions, but its value for other invasive dental procedures is unproved. It was calculated that, for every 10000 extractions in at risk patients, appropriate prophylaxis will prevent 5.7 deaths and a further 22.85 cases of non-fatal IE. This represents a saving in the costs of hospital care of Ł289 600 for 10000 extractions.

Conclusion-Prophylaxis to prevent IE in at risk patients undergoing dental extraction is highly cost effective. Net savings each year throughout the United Kingdom, that might be achieved by improving the existing proportion of such patients given antibiotics from its present level of about $50 \%$ would amount to $€ 2.5$ million and would prevent over 50 deaths.
\end{abstract}

(Br Heart f 1993;70:79-83)

Infective endocarditis (IE) is one of the few fatal consequences of dental treatment and thus its prevention has long been a subject of interest of dentists and doctors alike. Although $15 \%$ of cases are attributable to dental procedures ${ }^{1}$ and there is no direct proof that antibiotic prophylaxis is efficacious, ${ }^{2}$ it has long been established practice to use prophylaxis in at risk patients where the dental procedure is likely to produce a bacter- aemia. ${ }^{34}$ The rarity of cases of IE ensures that we are unlikely ever to obtain proof of the efficacy of prophylaxis but there is a wealth of evidence from experimental animal models ${ }^{56}$ to justify its use as well as a lack of reported cases of failed prophylaxis ${ }^{78}$ and a stable incidence of the disease despite an increasing pool of susceptible people. ${ }^{9}$

Several authors have questioned the continued use of prophylaxis for certain valve disorders $^{1011}$ whereas others have suggested its more widespread use. ${ }^{12}$ Apart from the lack of direct evidence of its efficacy other problems associated with its use are the side effects of the antibiotic prophylaxis (as many patients have to be given prophylaxis to prevent each case $)^{10}$ and the question of which patients to give prophylaxis to (as the risk factors are not well defined and many of the patients who develop IE after dental treatment have no known risk factors). ${ }^{1}$

Recently van der Meer et $a l^{13}$ and others ${ }^{14}$ have called into question the use of prophylaxis for most of those at risk on the basis that IE after dentistry is so rare, and they have called for a cost benefit analysis of this widespread practice. We have carried out such a study with United Kingdom data and where this is deficient, with our own data generated in Grampian.

\section{Materials and methods}

Cost effectiveness is determined by five factors:

(a) The cost of providing the recommended prophylaxis (a statutory dose of amoxycillin $(3 \mathrm{~g})$ after operation is $£ 2.36$ ).

(b) The risks and costs associated with reactions to penicillin. (The risk of anaphylactic reaction is taken from published sources).

(c) The risks of contracting IE in the absence of prophylaxis.

(d) The cost of treating survivors.

(e) The cost of treating fatalities.

Items $(c)$ to $(e)$ require further explanation.

CALCULATING THE RISK OF CONTRACTING IE We used published sources and where they were lacking, local data. We used a method similar to that of Clemans and Ransohoff. ${ }^{10}$ As IE is not a notifiable disease there are no good data on its incidence. We base our estimates on the number of known deaths from IE annually. If we assume for the moment 
that prophylaxis is $100 \%$ effective, the risk of at risk patients contracting IE and dying in the absence of prophylaxis may be calculated by the equation:

IE deaths in at risk patients

Risk $=$ after high risk procedure

High risk procedures undertaken in at risk patients without prophylaxis

We derive the number of IE deaths in at risk patients after high risk procedures by finding the number of deaths for which IE is either a mentioned or an inferred cause. This information is provided by the Office of Population Census and Surveys (OPCS) for England and Wales during 1985 and $1986 .{ }^{15} 16$ The mean figure for these two years is 482 deaths. Of these about $15 \%$ are after dentistry. ${ }^{17}$ Thus 72.3 deaths from IE a year will result from dental procedures. Not all of these, however, will have been in high risk patients. Bayliss et al estimated that $60 \%$ of the patients developing IE after dentistry are in a high risk group. ${ }^{1}$ Our crude estimate is that about 43.4 deaths will occur in at risk patients after high risk procedures. According to McGowan, about $95 \%(41 \cdot 2)$ are attributable to dental extractions, with other at risk procedures likely to induce bacteraemia (scaling, periodontal surgery, root canal treatment and intraligamentary injection) responsible for the remaining $5 \%$ of cases of IE..$^{18}$

The number of high risk procedures in at risk patients without prophylaxis may also be estimated. Annually about $23 \cdot 7$ million people in England and Wales undergo high risk procedures performed under the NHS. ${ }^{19}$ As the NHS accounts for about $88 \%$ of dental procedures undertaken, ${ }^{20}$ we estimate the total annual number of high risk procedures as 26.9 million. Of these about $5 \%$ of patients will have cardiac valvar lesions. ${ }^{21} 22$ This means that about 1.35 million high risk procedures will be undertaken on at risk patients each year. In a recent study from Aberdeen we found that $49 \%$ of patients did not receive appropriate prophylaxis. ${ }^{23}$ If our estimate of the numbers receiving antibiotics is correct the number of high risk procedures on at risk

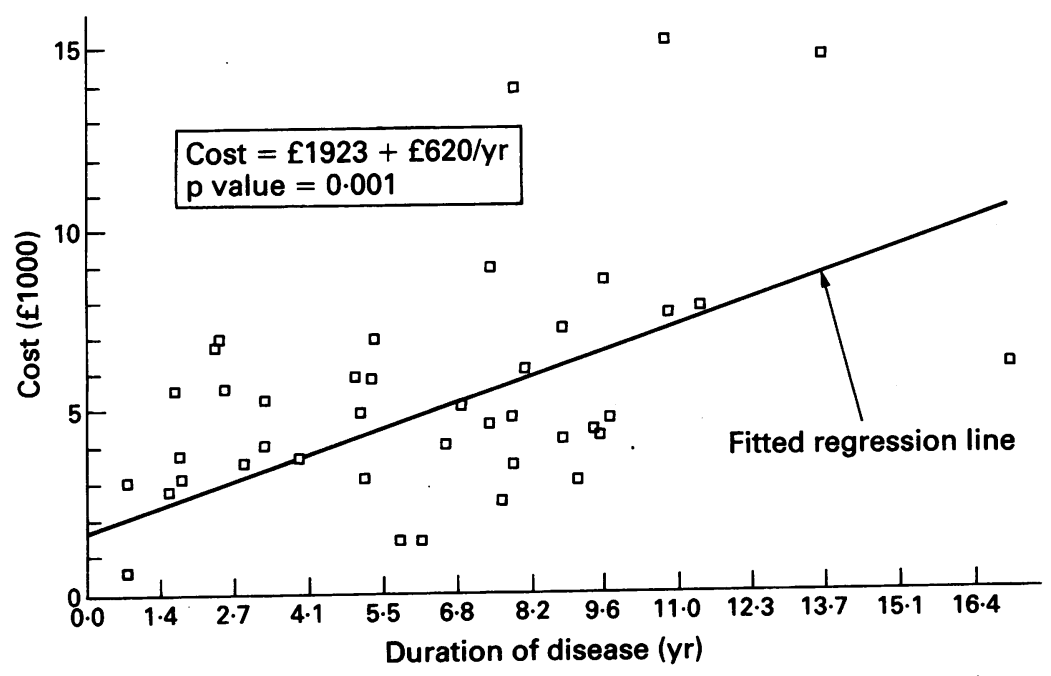

Relation between cost of care and survival after infective endocarditis. patients undertaken in the absence of prophylactic cover is about 670000 a year in England and Wales.

CALCULATING THE COSTS OF TREATING IE Costs were calculated from an inspection of the notes of 63 patients who had had IE in Grampian over the decade 1980-90. Costs of a stay in hospital, valve replacement operations, and out-patient visits were supplied by the health authority. For survivors we only included those cases where there was bacteriological support for the clinical diagnosis. For the fatalities (patients not surviving a first episode of IE) we included patients whose certified cause of death included infective endocarditis and whose endocarditis had been confirmed either bacteriologically or by the presence of vegetations at post mortem examination. As many of the patients whose notes were inspected will continue to require care for many years, lifetime costs for their care were predicted statistically. As in normal accounting practice we discounted at $6 \%$ a year to adjust for the extended period during which costs were incurred.

\section{Results}

THE EFFECTS OF PROVIDING PROPHYLAXIS FOR HIGH RISK PATIENTS AFTER ALL AT RISK DENTAL PROCEDURES

As there are about 43.4 deaths from a total of 670000 at risk people undergoing high risk procedures without prophylaxis, the risk of death for this group is about $0 \cdot 65 / 10000$ procedures. As the mortality is about $20 \%{ }^{17}$ the risk of non-fatal IE is 2.6 cases $/ 10000$ procedures.

Our estimates of the hospital cost of treating endocarditis are $£ 3392$ for a fatality and $£ 11831$ for a survivor (at 1991/92 prices). The figure shows the relation between costs and survival after endocarditis. The rising costs largely reflect the fact that some patients will need to undergo repeated valve replacement operations.

The net cost saving attributable to prophylaxis is the saving associated with the reduced number of people needing treatment after contracting IE less the cost of antibiotics and the treatment of allergic reactions (assumed to be in the region of $f 500$ ). The savings for an illustrative population of 10000 at risk people undergoing high risk procedures would be in the region of $£ 7750$.

THE EFFECT OF RESTRICTING PROPHYLAXIS FOR HIGH RISK PATIENTS TO DENTAL EXTRACTIONS

As $95 \%$ of cases of IE associated with dental treatment are attributable to dental extractions and extractions account for only a small proportion of dental procedures, it follows that the risk for those people undergoing extractions must be far greater than the risk of people undergoing other at risk dental procedures. As this is masked within the overall figures already presented, we used the same methods to calculate the risks and savings 
Table 1 Potential cost savings from the provision of prophylaxis for high risk groups before dental extractions

\begin{tabular}{lcc}
\hline & $£ / 10000$ extractions & $\begin{array}{l}\text { United Kingdom savings } \\
\text { over existing practice } \\
(£)\end{array}$ \\
\hline $\begin{array}{l}\text { Savings associated with } \\
\text { reduction in fatalities }\end{array}$ & 19369 & 183173 \\
$\begin{array}{l}\text { Savings associated with } \\
\text { reduction in morbidity }\end{array}$ & 270232 & 2555584 \\
$\begin{array}{l}\text { Gross savings attributable } \\
\text { to prophylaxis }\end{array}$ & 289600 & 2738747 \\
$\begin{array}{l}\text { Cost of prophylaxis } \\
\text { Cost of treating reactions } \\
\text { to antibiotics }\end{array}$ & 23600 & 223185 \\
$\begin{array}{l}\text { Net savings attributable } \\
\text { to prophylaxis }\end{array}$ & 2000 & 18914 \\
\hline
\end{tabular}

associated with prophylaxis for extractions alone. The risk was calculated as $5 \cdot 7$ deaths for 10000 extractions, which amounts to a saving of $£ 264000$ (table 1).

THE EFFECTS OF PROVIDING PROPHYLAXIS TO HIGH RISK PATIENTS AFTER HIGH RISK PROCEDURES OTHER THAN EXTRACTIONS As most of the cases of IE after dentistry are associated with extractions, it follows that few are associated with other high risk procedures for which prophylaxis has traditionally been provided. ${ }^{4}$ We calculate that the risk of death for these procedures is very low. Our figures suggest that giving prophylaxis will save only three lives in a million procedures. The estimates of frequency of reactions to penicillin range from one to 10 fatalities for a million courses. Thus it is by no means clear that prophylaxis for high risk procedures other than extraction would result in a net saving of life.

With the extremely small number of cases of IE averted for high risk procedures other than extraction, the cost of antibiotics would exceed savings costs of treatment. The cost of providing antibiotics for these procedures amounts to $£ 23727 / 10000$ procedures. Assuming penicillin fatalities at one for a million courses of antibiotic, the cost of a life saved would be in the region of $£ 1$ million.

\section{Discussion}

SAVINGS THAT MIGHT BE ACHIEVED BY IMPLEMENTING POLICIES IMPLIED BY THESE RESULTS

Current recommendations emphasise the use of prophylaxis for all dental procedures likely

Table 2 Sensitivity analysis: how different assumptions affect calculation of the number of fatalities averted /10 000 procedures

\begin{tabular}{|c|c|c|c|c|}
\hline \multirow[b]{3}{*}{ Assumption } & \multicolumn{4}{|c|}{ Deaths $/ 10000$ extractions } \\
\hline & \multicolumn{2}{|c|}{ Extractions only } & \multicolumn{2}{|c|}{ Other invasive procedures } \\
\hline & Adverse & Favourable & Adverse & Favourable \\
\hline $\begin{array}{l}\text { Death/yr after IE } \\
\text { IE of dental origin(\%) } \\
\text { IE occuring in high risk patients (\%) } \\
\text { High risk patients in the population (\%) } \\
\text { Patients not receiving prophylaxis (\%) } \\
\text { Efficacy of prophylaxis(\%) } \\
\text { Penicillin deaths /million } \\
\text { All extreme assumptions }\end{array}$ & $\begin{array}{l}2 \cdot 54 \\
1 \cdot 89 \\
4 \cdot 27 \\
4 \cdot 91 \\
3 \cdot 62 \\
1 \cdot 87 \\
5 \cdot 61 \\
0 \cdot 24\end{array}$ & $\begin{array}{l}5 \cdot 7^{\star} \\
9 \cdot 51 \\
6 \cdot 18 \\
5 \cdot 7^{\star} \\
5 \cdot 7^{\star} \\
5 \cdot 7^{\star} \\
5 \cdot 7^{\star} \\
10 \cdot 3\end{array}$ & $\begin{array}{r}0.01 \\
0.00 \\
0.02 \\
0.02 \\
0.01 \\
0.00 \\
-0.06 \\
-0.10\end{array}$ & $\begin{array}{l}0.03^{\star} \\
0.05 \\
0.03 \\
0.03^{\star} \\
0.03^{\star} \\
0.03^{\star} \\
0.03 \\
0.06\end{array}$ \\
\hline
\end{tabular}

*In those cases where extreme cases were not available from publications, we quote the results from our best guess figure. to induce a bacteraemia. This includes not only extraction but scaling, peridontal surgery, and more recently intraligamentary injection. ${ }^{24}$

Our findings suggest that we should limit prophylaxis before dentistry to those patients undergoing dental extractions. As prophylaxis is currently provided to only about $50 \%$ of patients thought to be at high risk, primarily due to poor awareness by dentists as to which of their patients is at risk, ${ }^{23}$ savings might be achieved by extending antibiotic cover for dental extractions and reducing such cover for other high risk procedures.

If we were to achieve $100 \%$ prophylaxis cover before extractions for high risk patients, net savings over existing practice would amount to $£ 2.5$ million (principally from the reduction in the number of cases of endocarditis requiring treatment) and 56 lives would be saved each year in the United Kingdom.

If we were to discontinue the practice of providing prophylaxis before invasive dentistry other than extractions, we might anticipate savings throughout the United Kingdom of $£ 1.9$ million a year (principally from the reduction in the cost of providing antibiotics). The possible total savings by implementing such policies are therefore in the region of $£ 4.4$ million.

We must remember that our data might mask important differences. In the findings presented by Bayliss et al half the patients dying of infective endocarditis and with a known cardiac lesion had a prosthetic valve..$^{25}$ There are no reliable data on the prevalence of prosthetic valves within the population, but we expect the prevalence to be small in comparison with patients having a cardiac lesion but no prosthetic valve so the risk for patients with a prosthetic valve will be relatively high. Similarly patients who have survived an episode of IE seem to be at high risk. This suggests that prophylaxis is indicated for these groups of patients for any invasive dental procedure. Our results emphasise the importance of identifying as precisely as possible the patients and procedures for whom prophylaxis is being considered, something that is difficult as the underlying prevalence of various at risk abnormalities is not known.

\section{SENSITIVITY ANALYSIS}

Many of the assumptions used in determining the risk of contracting IE are a matter for debate. We have used figures that seem to us to be the most reliable; however, we also tested the robustness of our conclusions by investigating the effects of other figures quoted in relevant publications. Table 2 shows the effects of varying our assumptions. Sensitivity analysis is performed for both the case of providing prophylaxis for dental extractions and the case of invasive dental procedures other than extractions. We consider the effects of using assumptions both adverse and favourable to the case for prophylaxis. (A list of references can be supplied on demand.)

Our conclusions regarding extractions vary 
with different assumptions used in the calculation of risk, but in all cases the least favourable assumptions nevertheless result in a reduction in the number of fatalities.

Our estimates of the number of cases of IE a year in the United Kingdom are based on OPCS statistics for England and Wales for deaths from IE both mentioned and inferred. This gives a higher (although we believe realistic) estimate of the number of cases of IE than is sometimes quoted. Previous estimates have been based on notifications of death and are between 1000 and 1500 cases a year. Our estimate is equivalent to 2410 cases a year. We think that many cases are never diagnosed before death. In our unpublished review of cases in Grampian for the decade 1980-90 10 of 89 possible cases were diagnosed unexpectedly at postmortem examination. With postmortem examination rates for hospital death at about $20 \%$ (Dr K Kerr, Aberdeen Royal Hospitals Trust, personal communication) this will inevitably lead to a severe underestimate of cases. Nevertheless sensitivity analysis with a lower figure of 215 deaths a year still results in a saving of 2.54 lives and a saving of $£ 264000$ to the health service for 10000 cases given prophylaxis.

We use a figure of $20 \%$ for the mortality after IE. This may be considered by some to be high. As our calculations are based on the number of fatalities, had we used a lower figure for mortality, the number of survivors would have increased accordingly. A policy of prophylaxis would then provide the potential for even greater cost savings.

There are other consequences of reducing the incidence of IE that are extremely difficult to quantify, and which we have therefore omitted from our calculations. Importantly there are the suffering caused to survivors and the loss of economic output. The inclusion of these factors would serve to strengthen the case for expanding the use of prophylaxis.

Similarly our figures could overestimate the benefits of prophylaxis although, we believe, only in minor ways. For example, prophylaxis is unlikely to be $100 \%$ effective. Even if only $50 \%$ effective it would still be worth undertaking, resulting, as it does, in a reduction in the number of IE fatalities by 1.87 for 10000 extractions (table 2). The lack of case reports of failed prophylaxis where currently recommended regimes are used $^{8}$ does suggest that it is very effective. Also we did not cost the impaired health such as brain damage that could follow a severe reaction to a drug. We could find no published data but this is likely to be a rare event.

Sensitivity analysis on the risk of dying from IE after dental procedures other than extractions also confirms our earlier conclusions. Even taking all the most favourable assumtions we see a saving only of six deaths for a million extractions. This compares with a loss of 10 deaths for a million if all the worst extreme assumptions proved to be true. There are no figures that we could find that would radically alter our results.

In conclusion we believe that prophylaxis to prevent IE in at risk patients undergoing extraction is cost effective even when the assumptions on which this conclusion is based are subject to stringent scrutiny. Consequently there is scope for expanding the use of prophylaxis in dental practice - for example, by improving communication between doctors and dentists so that the dentists are more aware of at risk patients, ${ }^{23}$ and perhaps also by giving prophylaxis to more elderly patients where the incidence of predisposing cardiac lesions is likely to be much higher. Alternatively, as most cases of IE associated with dental procedures are due to extractions, the case for prophylaxis for other procedures that have traditionally been regarded as high risk is less clear. It might be wise to reduce the use of prophylaxis for other procedures such as scaling where the cost of antibiotics and antibiotic reactions counters the potential benefits of preventing IE, restricting its use before scaling and other lower risk procedures to those at the very highest risk of IE-for example, patients with prosthetic valves or survivors of earlier episodes of infective endocarditis.

The Health Services Research Unit is funded by the Chief Scientist's Office of the Scottish Office Home and Health Department (SOHHD), however, the opinions expressed in this communication are those of the authors, not those of the SOHHD.

1 Bayliss R, Clarke C, Oakley C, Somerville W, Whitfield AGW. The teeth and infective endocarditis. $\mathrm{Br}$ Heart 1983;50:506-12.

2 Gould IM. Prevention of infective endocarditis. Br Dent 1988;164:31.

3 Gould IM. Chemoprophylaxis for bacterial endocarditisa survey of current practice in London. Fournal of Health Economics 1984;14:379-94.

4 Gould IM. Current prophylaxis for prevention of infective endocarditis. Br Dent $\mathcal{F}$ 1990;166:409-10.

5 Moreillon P, Francioli P, Overholser D, Meylan P, Glauser MP. Mechanisms of successful amoxicillin prophylaxis of experimental endocarditis due to phylaxis of experimental endocarditis due

6 McGowan DA, Nair S, MacFarlane TW, Mackenzie D. Prophylaxis of experimental endocarditis in rabbits using one or two doses of amoxycillin. Br Dent $\mathcal{F}$ 1983;155:88-90

7 Denning DW, Cassidy M, Dougall A, Hillis WS. Failure of single dose amoxicillin as prophylaxis against endocarditis. BMF 1984;289:1499-1500

8 Durack DT, Bisno AL, Kaplan EL. Apparent failures of endocarditis prophylaxis. Analysis of 52 cases submitted to a national registry. $¥ A M A 1983 ; 250: 2318-22$.

9 Watanakunakorn $C$. Infective endocarditis as a result of medical progress. Am $\mathcal{F}$ Med 1978;64:917-9.

10 Clemens JD, Ransohoff DF. A quantitative assessment of pre-dental antibiotic prophylaxis for patients with mitral-valve prolapse. Fournal of Chronic Diseases mitral-valve pro

11 Hickey AJ, MacMahon SW, Wilcken EL. Mitral valve prolapse and bacterial endocarditis: when is antibiotic prolapse and bacterial endocarditis: when is antibiotic

12 Oakley C, Somerville W. Prevention of infective endocakley C, Somerville W. Prevention

13 van der Meer JTM, van Wijk W, Vandenbroucke JP, Valkenburg HA, Michel MF. Efficacy of antibiotic prophylaxis for prevention of native-valve endocarditis: nationwide case-control study in the Netherlands. Lancet 1992;339:135-9.

14 Editorial. Chemoprophyalaxis for infective endocarditis: faith, hope, and charity challenged. Lancet 1992;339: $525-6$.

15 Office of Population Census and Surveys. Mortality statistics: England and Wales, London: HMSO, 1985.

Office of Population Census and Surveys. Mortality statistics: England and Wales, London: HMSO, 1986.

17 Skehan JD, Murray M, Mills PG. Infective endocarditis: Skehan JD, Murray M, Mills PG. Infective endocarditis:
incidence and mortality in the North East Thames incidence and mortality in the

18 McGowan, D A. Experimental evidence on the prevention of infective endocarditis in dentistry. In: Cawson RA, 
ed. The nature and prevention of bacterial endocarditis Oxford: Medicine Publishing Foundation, 1981, 15-21. 19 Dental Estimates Board. Annual report 1988/89. 1989, (Unpublished)

20 Todd JE, Lader D. Adult dental health 1988 United Kingdom, London: HMSO, 1991.

21 Doyle YG, Fenlon MR. Medical screening of 1500 patients in a dental surgery: a prospective study. $\mathcal{f} R$ Coll Gen Pract 1989;39:415-7.

22 McGowan DA, Tuohy O. Dental treatment of patients with valvular heart disease. Br Dent f 1968;124:519.

23 Buckingham JK, Gould IM, Tervitt G, Williams S. Prevention of endocarditis: communication between doctors and dentists. Br Dent $\mathcal{F} 1992 ; 172: 414-5$.

24 Simons NA, Ball AP, Cawson RA, et al. Antibiotic prophylaxis and infective endocarditis. Lancet 1992;339: phylaxis

25 Bayliss R, Clarke C, Oakley CM, Somerville W, Whitfield AGW, Young SEJ. The microbiology and pathogenesis of infective endocarditis. Br Heart f 1983;50:513-9.

\title{
ABSTRACTS IN CARDIOLOGY
}

\section{Restenosis and myointimal hyperplasia}

Restenosis caused by intimal vascular smooth muscle hyperplasia after coronary angioplasty or bypass surgery is a major problem, both clinically and economically. There is therefore considerable interest in the mechanisms controlling intimal smooth muscle proliferation. Heparin is an inhibitor of smooth muscle cell proliferation both in vitro and in vivo. Chan et al describe an abnormal growth regulatory response to heparin in vascular smooth muscle cells cultured from patients with restenotic lesions.

Chan et al had to face the usual difficulties of investigators trying to obtain normal human control tissue. Their controls therefore comprised various arteries from two organ donors and saphenous vein and internal mammary artery from patients undergoing primary revascularisation procedures. They used saphenous vein as the normal vessel control for patients with restenosis.

Two caveats apply to the interpretation of these results and their clinical application. Chan et al isolated smooth muscle cells from the whole vessel wall including medial smooth muscle cells. Medial smooth muscle cells greatly outnumber those in the intima, particularly in the veins and normal arteries. These results could therefore be a consequence of comparing smooth muscle cell populations in the intima and the media. In addition, up to $40 \%$ of the control patients undergoing primary bypass surgery will develop restenoses; their smooth muscle cells may already have been showing abnormal growth regulatory behaviour. This may explain the overlap in growth inhibition by heparin seen in the study.

Chan et al found that heparin inhibited growth in smooth muscle cells derived from patients with restenosis significantly less than those from controls. This aberrant response was not confined to cells derived from restenotic lesions: it was also found in smooth muscle cells cultured from apparently normal vessels from the same patient.

As the validity of animal models of restenosis is increasingly questioned, the importance of studying the disease in humans increases. Chan et al's data suggest that patients liable to restenosis have a generalised abnormality of smooth muscle cell proliferation in response to heparin, which may reflect a wider abnormality in the control of the growth of smooth muscle cells.

Prospective studies of the behaviour of human intimal smooth muscle cells might help to identify those at risk of restenosis and lead to therapeutic interventions to prevent restenosis.

SA THORNE

\section{Abnormal growth regulation of vascular smooth muscle cells by heparin in patients with restenosis}

\author{
Philip Chan, Mahendra Patel, Laura Betteridge, Euan Munro, Michael Schachter, fohn Wolfe, Peter Sever
}

Proliferation of vascular smooth muscle cells (VSMC) underlies myointimal hyperplasia, which can lead to restenosis after angioplasty and vascular surgery. We propose that some individuals have an intrinsic capacity for this exaggerated response to vascular injury, partly through decreased sensitivity to the physiological growth inhibitor heparin We investigated the effect of heparin on VSMC from restenotic lesions and from apparently normal vessels of the same patients, and VSMC from control patients undergoing primary bypass procedures. Cells from patients with restenosis (both restenotic lesion and undiseased vein) showed much lower sensitivity to growth inhibition by heparin than the controls (median inhibition 8 (95\% CI-2 to 25) v $22(15-44) \%, \mathrm{p}<0001)$; this finding suggests aberrant growth regulation in these cells. (Lancet 1993;341:341-2.) 